\title{
Degradation Behavior of Concrete after Freeze-Thaw Cycles and Then Exposure to High Temperatures
}

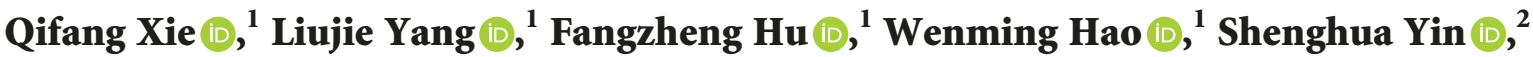 \\ and Lipeng Zhang ${ }^{1}$
}

\author{
${ }^{1}$ School of Civil Engineering, Xi'an University of Architecture and Technology, Xi'an, Shannxi 710055, China \\ ${ }^{2}$ Yaqi Group Co., Ltd., Ganzhou, Jiangxi 341400, China
}

Correspondence should be addressed to Qifang Xie; xieqfgh@xauat.edu.cn

Received 31 March 2019; Revised 27 May 2019; Accepted 16 June 2019; Published 2 July 2019

Academic Editor: Antonio Caggiano

Copyright (c) 2019 Qifang Xie et al. This is an open access article distributed under the Creative Commons Attribution License, which permits unrestricted use, distribution, and reproduction in any medium, provided the original work is properly cited.

\begin{abstract}
Concrete behavior usually degrades due to freeze-thaw cycles, fire, or both. Existing studies on the degradation behavior of concrete due to exposure to high temperatures were primarily focused on unfrozen concrete. In this paper, the degradation behavior of damaged concrete, after different freeze-thaw cycles $(25,35,45$, and 55 cycles $)$, exposure temperatures $\left(20^{\circ} \mathrm{C}, 300^{\circ} \mathrm{C}\right.$, $400^{\circ} \mathrm{C}$, and $500^{\circ} \mathrm{C}$ ), and cooling methods (water-cooled and air-cooled), was tested with seventy-five prism specimens. The degradation behavior of the damaged concrete, such as surface characteristics, weight loss, compressive strength, peak strains, and elastic modulus, was studied and analyzed. Results show that (i) the surface color of the concrete does not change significantly throughout the test. As the number of freeze-thaw cycles and temperatures increase, the weight loss of the concrete specimens increases gradually. (ii) After freeze-thaw cycles, the relative strengths and elastic modulus of the concrete specimens significantly degrade compared with those of the unfrozen ones at same temperatures. (c) At elevated number of freeze-thaw cycles and exposure temperatures, the peak strain of the concrete increases gradually. (d) Cooling methods have different effects on the degradation of concrete under different number of freeze-thaw cycles. Finally, a uniaxial compression constitutive model for concrete after freeze-thaw cycles and then exposure to high temperatures was established and a good agreement was observed with test results.
\end{abstract}

\section{Introduction}

Concrete structures are sometimes subjected to fire and also freeze-thaw cycles, which will degrade the behavior of the concrete and then the structures. It is necessary to clearly understand the behavior of degradation of the concrete caused by freeze-thaw cycles, fire, or both.

Many researchers have investigated the performance of the concrete after exposure to high temperatures, including the change in the microstructure [1-3], the degradation of mechanical performance of ordinary concrete [4-7] and high-strength concrete $[8,9]$, and the effect of different cooling methods $[10,11]$. It is noted that the mechanical behavior of concrete (both ordinary concrete and highperformance concrete) after exposure to high temperatures degraded to different degrees and is affected by cooling methods.

For the concrete structures in cold areas, the change of concrete performance after freeze-thaw cycles is critical. In order to predict the performance of concrete under freezethaw cycles, a model was proposed based on the damage accumulation theory [12]. For the microstructure observation of concrete and damage assessment after freeze-thaw cycles, X-ray and CT are widely used $[13,14]$. Generally, researchers pay more attention to the degradation of mechanical properties after freeze-thaw cycles, for both ordinary concrete $[15,16]$ and air-entrained concrete $[17,18]$.

The above studies are mainly concerned with the degradation of concrete after freeze-thaw cycles or exposure to high temperatures only, and few research studies concerned 
with the degradation under two or more effects. Xie et al. [19] studied the high-temperature resistance of concrete after carbonization and proposed a constitutive equation for predicting the compressive properties of carbonized concrete after exposure to high temperatures. Mao et al. [20] focused on the durability of fly ash concrete under alternative interactions of freeze-thaw and carbonization and used microscopic techniques to reveal the damage mechanisms of the concrete. Cheng et al. [21] studied the effect of crack, freeze-thaw, and carbonization on reinforced concrete specimens in practical engineering through a series of tests. Wu and $\mathrm{Wu}$ [22] studied the behavior of the concrete subjected to high temperatures and then freeze-thaw cycles and concluded that the durability of freeze-thaw for the concrete was evidently reduced after exposure to high temperatures. However, the degradation of the concrete subjected to freeze-thaw cycles and then high temperatures (i.e., a reverse experimental processing [22]) was seldom reported. In cold regions, concrete structures with freeze-thaw damage may also suffer hightemperature (fire) damage. Thus, the research on the degradation of the concrete after freeze-thaw cycles and then exposure to high temperatures is very significant to evaluate the durability of concrete structures.

In this study, a series of experimental studies on the concrete specimens after freeze-thaw cycles and then exposure to high temperatures were conducted. The objectives are to obtain the degradation laws of mechanical properties and establish the constitutive model for uniaxial compression concrete after freeze-thaw cycles and then high-temperature exposures.

\section{Experimental Program}

2.1. Materials. Materials used in the tests are a same batch commercial concrete of $\mathrm{C} 35$, which is widely used in practical construction. The detailed mixture proportions of the concrete are shown in Table 1.

2.2. Designing and Grouping of Specimens. Seventy-five concrete prism specimens (i.e., twenty-five types each with 3 specimens) were prepared with a size of $100 \mathrm{~mm} \times$ $100 \mathrm{~mm} \times 300 \mathrm{~mm}$. Through 3 additional specimens, the average measured compressive strength of the 28-day cube without freeze-thaw and high temperatures was $32.2 \mathrm{MPa}$, and the standard deviation was 0.7 . All the specimens were poured and cured in accordance with the Chinese Standard for Test Method of Mechanical Properties on Ordinary Concrete (GB/T 50081-2002) [23] and divided into five groups and named as shown in Table 2.

\subsection{Freeze-Thaw Cycle Test of Concrete Specimens}

2.3.1. Test Apparatus of Freeze-Thaw Cycle Test. The KDRV9 concrete rapid freeze-thaw test machine (shown in Figure 1) was used in the freeze-thaw cycle test, consisting of 28 chambers.
2.3.2. Freeze-Thaw Cycle Test Methods and Process. The freeze-thaw cycle tests were performed by the rapid freezethaw method in accordance with the Chinese Standard for Test Methods of Long-Term Performance and Durability of Ordinary Concrete (GB/T 50082-2009) [24]. Detailed test procedures are as follows: the concrete specimens were cured for 24 days under standard conditions (temperature $20^{\circ} \mathrm{C} \pm 2{ }^{\circ} \mathrm{C}$ and humidity $\geq 95 \%$ ). Then, the concrete specimens were soaked in water of $20 \pm 2^{\circ} \mathrm{C}$ for 4 days for saturation. The water surface should be $20-30 \mathrm{~cm}$ higher than the top surfaces of the specimens. After that, the specimens were taken out of the water and then placed in a freeze-thaw device for testing. The temperature of the freeze-thawed specimen was reduced from $+3^{\circ} \mathrm{C}$ to $-16^{\circ} \mathrm{C}$ and then raised $+3^{\circ} \mathrm{C}$ every $2 \mathrm{~h}$ for each cycle.

2.3.3. Observations of Specimens after Freeze-Thaw Cycles. After the freeze-thaw cycle tests, the surface layers of the concrete specimens had different degrees of damage, as shown in Figure 2. From the figure, the following can be observed:

(a) At relatively small number of freeze-thaw cycles $(N=25$ or 35$)$, the cracks on the concrete surface were not obvious, and few superficial layers of concrete spalled off.

(b) At relatively large number of freeze-thaw cycles $(N=45$ or 55$)$, the surfaces of specimens spalled off severely, exposing coarse aggregates. The edges of the specimens became incomplete, especially at $N=55$.

\subsection{Thermal Treatment of Concrete Specimens}

2.4.1. Test Apparatus of Thermal Treatment. A high-temperature furnace with a working size of $1500 \mathrm{~mm} \times$ $500 \mathrm{~mm} \times 500 \mathrm{~mm}$ was used for thermal treatment (as shown in Figure 3), whose temperature ranged from room temperature to $+1000^{\circ} \mathrm{C}$ with $4^{\circ} \mathrm{C} / \mathrm{min}$ heating rate and precision $\pm 1^{\circ} \mathrm{C}$.

2.4.2. Thermal Treatment Test Methods and Process. A day after the freeze-thaw cycle test, thermal treatment test began. Firstly, the freeze-thawed concrete specimens were heated to $80^{\circ} \mathrm{C}$ and held for 24 hours to evaporate free water and capillary water [6]. Then, the temperature was elevated to the exposure temperature designed in Table 2 at a rate of $4^{\circ} \mathrm{C} /$ min and kept constant for $3 \mathrm{~h}$. Finally, the specimens were taken out of the furnace and then cooled by spray water or air-cooling.

2.4.3. Observations of Specimens after High Temperatures. The surface deterioration of concrete specimens after freezethaw cycles and exposure to high temperatures is shown in Figure 4. From the figure, the following can be clearly observed:

(a) With the increase of the number of freeze-thaw cycles, more and more cracks can be clearly seen on 
TABLE 1: Mixture proportions of concrete specimens.

\begin{tabular}{lcccc}
\hline Cement $\left(\mathrm{kg} / \mathrm{m}^{3}\right)$ & Water $\left(\mathrm{kg} / \mathrm{m}^{3}\right)$ & Coarse aggregate $\left(\mathrm{kg} / \mathrm{m}^{3}\right)$ & Fine aggregate $\left(\mathrm{kg} / \mathrm{m}^{3}\right)$ & $\mathrm{Fly}$ ash $\left(\mathrm{kg} / \mathrm{m}^{3}\right)$ \\
\hline 320 & 180 & 870 & 870 & 90 \\
\hline
\end{tabular}

TABLE 2: Details of the test specimens.

\begin{tabular}{|c|c|c|c|c|c|c|}
\hline Group & Notation & Freeze-thaw cycles & Number of specimens & Exposure temperature $\left({ }^{\circ} \mathrm{C}\right)$ & Exposure time (h) & Cooling method \\
\hline \multirow{5}{*}{ Group 1} & F0-T20W & 0 & 3 & 20 & 3 & Water \\
\hline & F0-T300W & 0 & 3 & 300 & 3 & Water \\
\hline & F0-T400W & 0 & 3 & 400 & 3 & Water \\
\hline & F0-T400A & 0 & 3 & 400 & 3 & Air \\
\hline & F0-T500W & 0 & 3 & 500 & 3 & Water \\
\hline \multirow{5}{*}{ Group 2} & F25-T20W & 25 & 3 & 20 & 3 & Water \\
\hline & F25-T300W & 25 & 3 & 300 & 3 & Water \\
\hline & F25-T400W & 25 & 3 & 400 & 3 & Water \\
\hline & F25-T400A & 25 & 3 & 400 & 3 & Air \\
\hline & F25-T500W & 25 & 3 & 500 & 3 & Water \\
\hline \multirow{5}{*}{ Group 3} & F35-T20W & 35 & 3 & 20 & 3 & Water \\
\hline & F35-T300W & 35 & 3 & 300 & 3 & Water \\
\hline & F35-T400W & 35 & 3 & 400 & 3 & Water \\
\hline & F35-T400A & 35 & 3 & 400 & 3 & Air \\
\hline & F35-T500W & 35 & 3 & 500 & 3 & Water \\
\hline \multirow{5}{*}{ Group 4} & F45-T20W & 45 & 3 & 20 & 3 & Water \\
\hline & F45-T300W & 45 & 3 & 300 & 3 & Water \\
\hline & F45-T400W & 45 & 3 & 400 & 3 & Water \\
\hline & F45-T400A & 45 & 3 & 400 & 3 & Air \\
\hline & F45-T500W & 45 & 3 & 500 & 3 & Water \\
\hline \multirow{5}{*}{ Group 5} & F55-T20W & 55 & 3 & 20 & 3 & Water \\
\hline & F55-T300W & 55 & 3 & 300 & 3 & Water \\
\hline & F55-T400W & 55 & 3 & 400 & 3 & Water \\
\hline & F55-T400A & 55 & 3 & 400 & 3 & Air \\
\hline & F55-T500W & 55 & 3 & 500 & 3 & Water \\
\hline
\end{tabular}

Note. "F\#" denotes the freeze-thaw cycles (F0 $=0$ cycles, F25 $=25$ cycles, F35 $=35$ cycles, F45 $=45$ cycles, and F55 $=55$ cycles); "T\#" denotes the target temperature of high-temperature heating; "W" or "A" represents water- or air-cooling (natural cooling), respectively. For example, "F25-T400W" indicates that the specimen subjected to $400^{\circ} \mathrm{C}$ after 25 freeze-thaw cycles and then cooled by the water spray method.

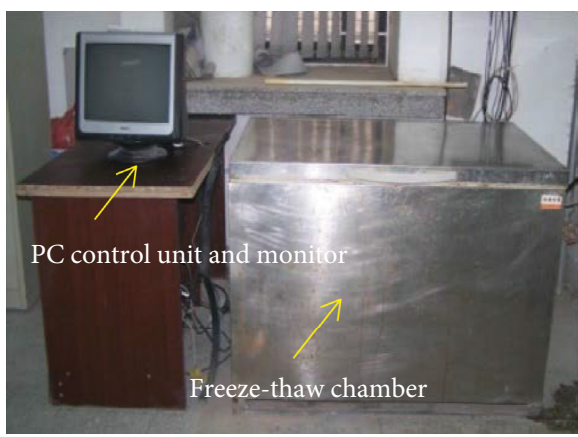

(a)

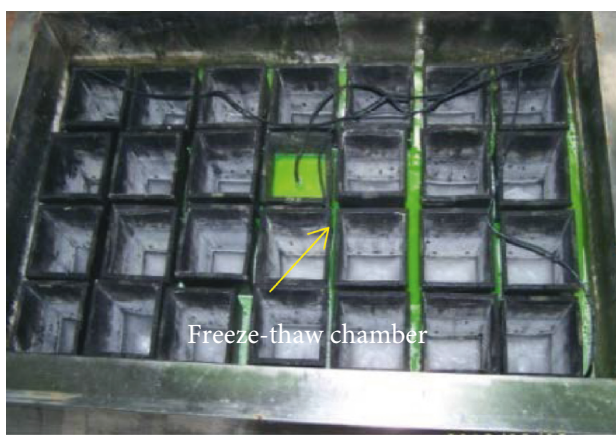

(b)

FiguRE 1: Freeze-thaw test apparatus.

the surfaces of the specimens under different temperatures.

(b) When the temperature is $400^{\circ} \mathrm{C}$, cracks can be clearly seen on the concrete surfaces, and the phenomenon was more obvious at relatively high freeze-thaw cycle levels. The surface layers of the mortar became loose and spalled off with the rising temperatures, especially when the temperature reached $500^{\circ} \mathrm{C}$.

(c) The surface colors of the specimens after different freeze-thaw cycles and exposure to high temperatures were almost the same irrespective of the cooling methods used. At $400^{\circ} \mathrm{C}$, the surface cracks of 


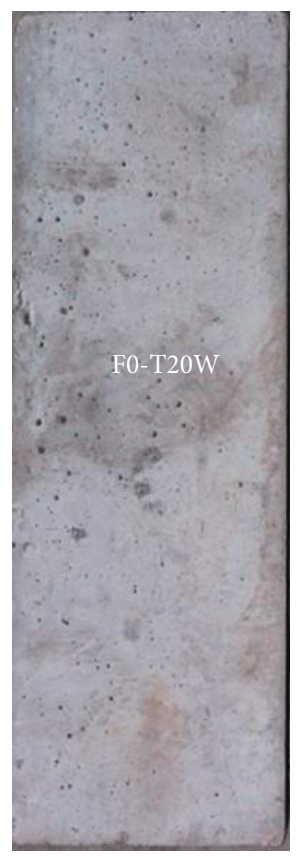

(a)

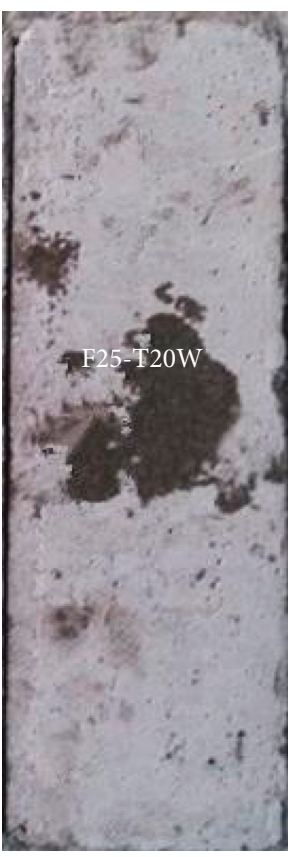

(b)

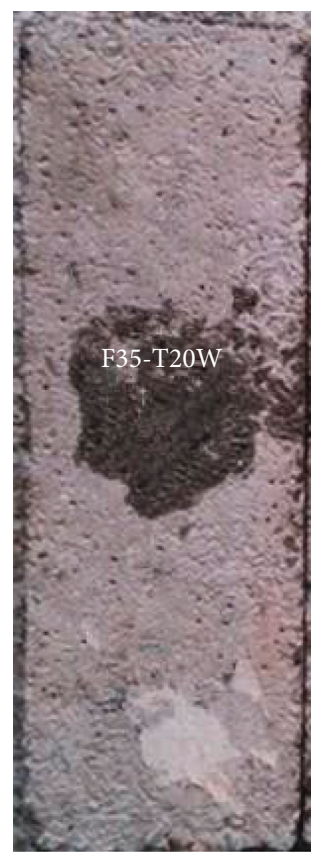

(c)

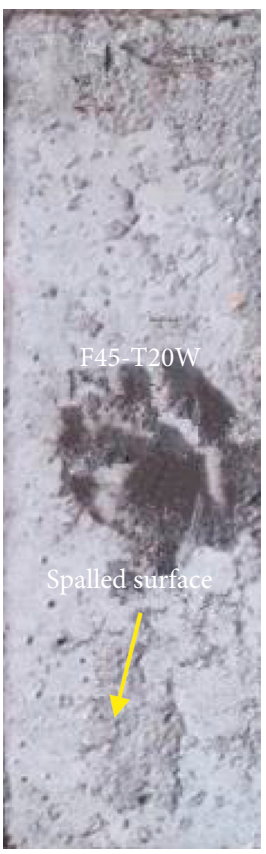

(d)

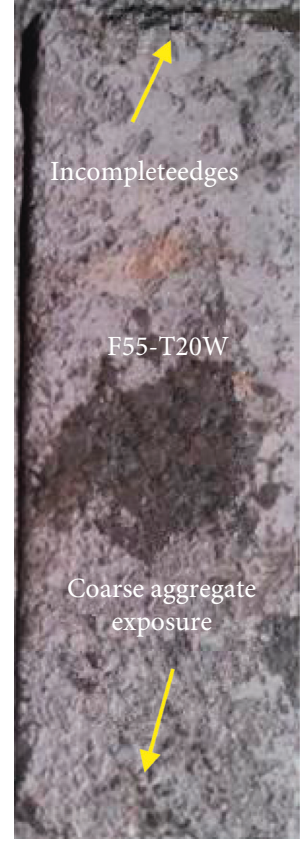

(e)

FIGURE 2: Lateral surface characteristics of specimens after different freeze-thaw cycles.

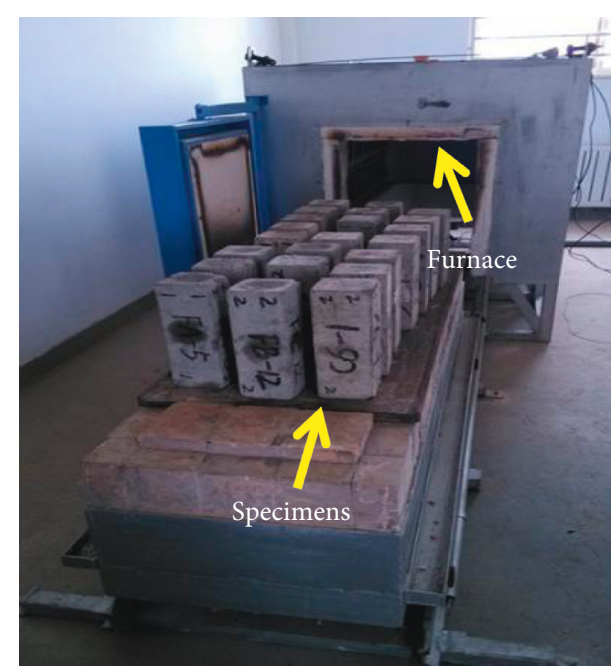

Figure 3: High-temperature experimental furnace.

the water-cooled concrete specimens were more obvious than those of the concrete specimens cooled by air, indicating that the damage caused by the watercooling method to the concrete specimen is greater.

\subsection{Loading Tests}

2.5.1. Loading Test Process and Apparatus. All the specimens were tested for uniaxial loading under a universal testing machine with a maximum capacity of $1000 \mathrm{kN}$. Four displacement transducers were, respectively, fixed at a distance of $50 \mathrm{~mm}$ from the upper and lower ends of the specimens (see Figure 5) to measure the deformation within $200 \mathrm{~mm}$ from the middle of the specimens, and the deformation of the middle part represents the deformation of the whole specimens. The loading rates of preloading and loading process were, respectively, controlled at $0.05 \mathrm{~mm} / \mathrm{min}$ and $0.2 \mathrm{~mm} / \mathrm{min}$. The loading rate near the peak point and the falling portion after the peak point were $0.05 \mathrm{~mm} / \mathrm{min}$, and then this rate was kept until the test specimen failure. The tests were performed in accordance with the Chinese Standard for Test Method of Mechanical Properties on Ordinary Concrete (GB/T 50081-2002) [23].

2.5.2. Observations during Loading Tests. The failure of the concrete specimens virtually reflected the process of the evolution of the microcracks inside the specimens. Due to the different degrees of damage, the time of occurrence of cracks in each specimen and its development during the loading process are different (see Figure 6), from which the following phenomena can be found:

(a) For the specimens with low exposure temperatures, few cracks appeared when the load was low, but the cracks developed quickly when the load was close to the failure load. By continuing compressive load, the concrete surface formed at least one obliquely penetrating crack due to compressive damage and then concrete specimens broke quickly.

(b) For the specimens subjected to high temperatures, cracks appeared at low load and also developed quickly when the load was close to the failure load. There were no obvious oblique cracks on the surface of the concrete, but the layer of the concrete spalled off severely.

(c) For the specimens with the same exposure temperatures, the more the freeze-thaw cycles were, the more the damage there would be. 


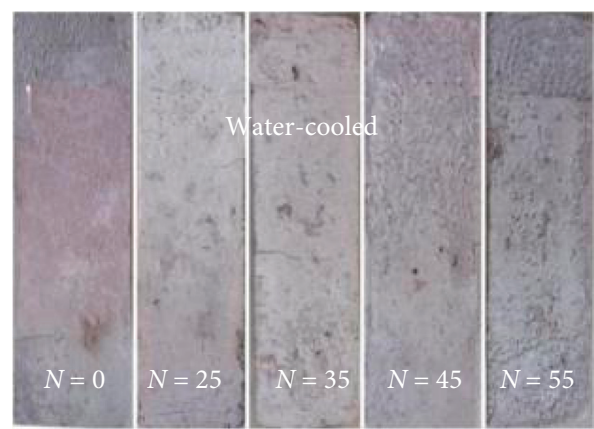

(a)

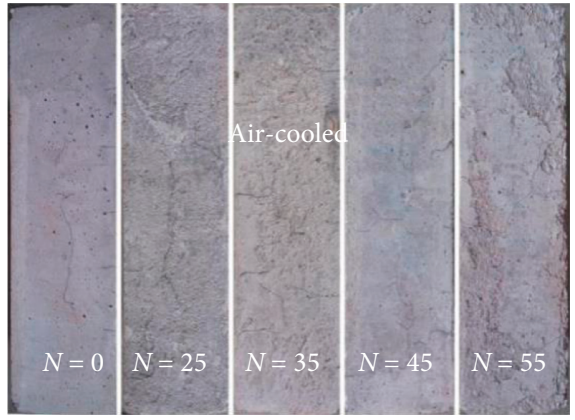

(c)

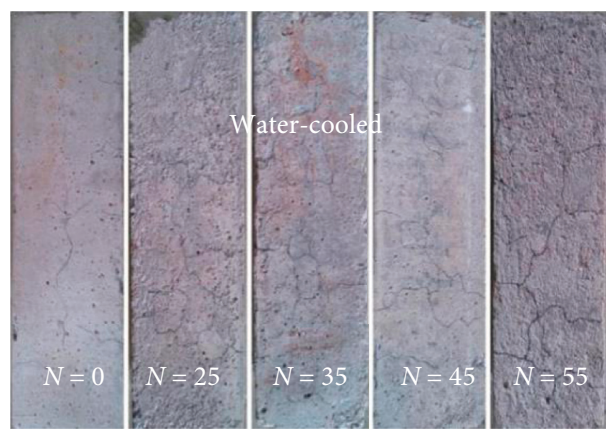

(b)
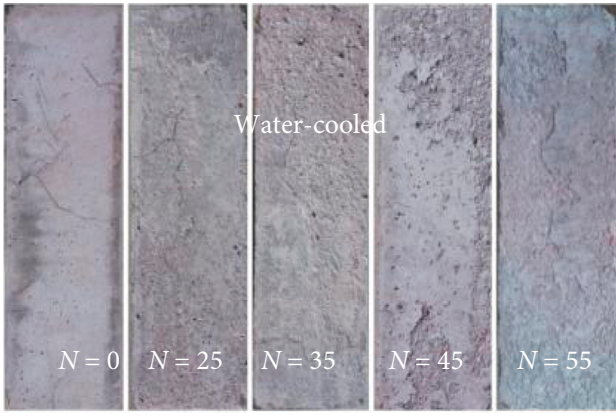

(d)

Figure 4: Surface degradation of freeze-thawed concrete specimens after different high temperatures: (a) $300^{\circ} \mathrm{C}$ (water-cooled), (b) $400^{\circ} \mathrm{C}$ (water-cooled), (c) $400^{\circ} \mathrm{C}$ (air-cooled), and (d) $500^{\circ} \mathrm{C}$ (water-cooled).

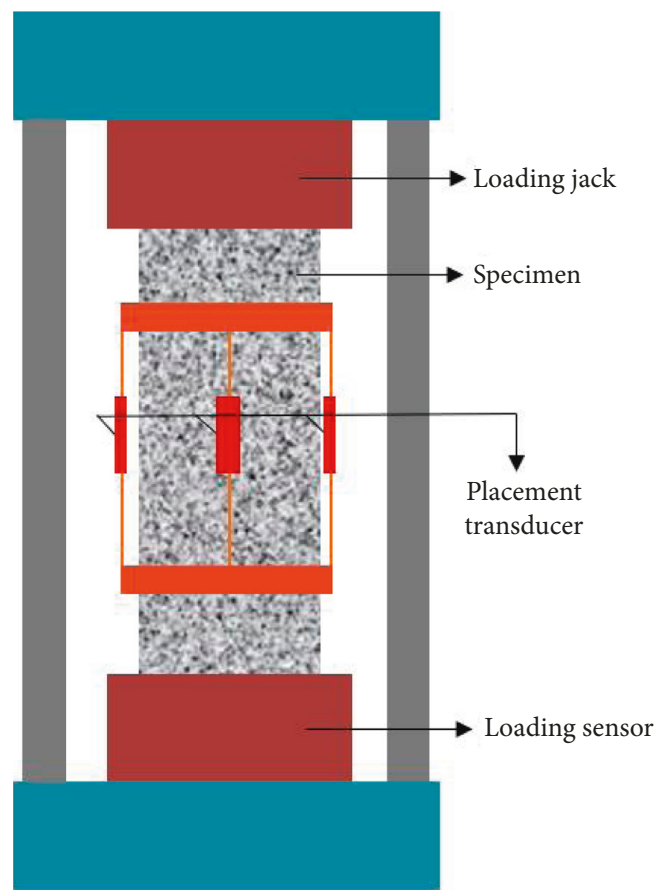

FIgURE 5: chematic of loading machine and displacement device.

\section{Test Results and Discussion}

3.1. Weight Loss of Concrete after Freeze-Thaw Cycles and Exposure to High Temperatures. In this investigation, the concrete specimens were first treated by freeze-thaw cycles and then subjected to high temperatures. $m_{\mathrm{af}} / m_{\mathrm{bf}}$ and $m_{\mathrm{at}} / m_{\mathrm{bt}}$ are used to represent the weight loss caused by freeze-thaw cycle treatment and high-temperature treatment, respectively. $m_{\text {af }}$ is the saturated mass of the concrete specimen after freezethaw cycles, and $m_{\mathrm{bf}}$ is the saturated mass of the concrete specimen before freeze-thaw cycles. $m_{\text {at }}$ is the dry mass of the concrete specimen after high-temperature treatment, and $m_{\mathrm{bt}}$ is the dry mass of the concrete specimen after freeze-thaw cycle treatment before high-temperature treatment.

The variation in concrete weight ratio (i.e., $m_{\mathrm{af}} / m_{\mathrm{bf}}$ and $\left.m_{\mathrm{at}} / m_{\mathrm{bt}}\right)$ with elevated number of freeze-thaw cycles and high temperatures are, respectively, shown in Figures 7 and 8 , and the following can be found:

(a) From Figure 7, as the number of freeze-thaw cycles increased, the weight ratio decreased slightly, only $0.8 \%$, meaning that the number of freeze-thaw cycles within the range of $0-55$ has a little effect on the weight loss of concrete.

(b) From Figure 8, in the case of same number of freezethaw cycles, the weight ratio reduced with elevated temperatures, and the degree of decline was higher than that caused by the freeze-thaw cycle of the previous stage. This is mainly due to the continuous evaporation of moisture inside the specimens with increasing temperatures.

3.1.1. Degradation of Compressive Strength. The degradation of relative compressive strength $f_{\mathrm{c}}(N, T) / f_{\mathrm{c}}(0,20)$ of watercooled concrete is shown in Figure 9. In which, $f_{c}(N, T)$ 

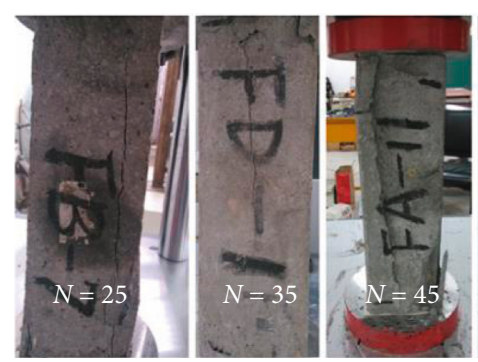

(a)
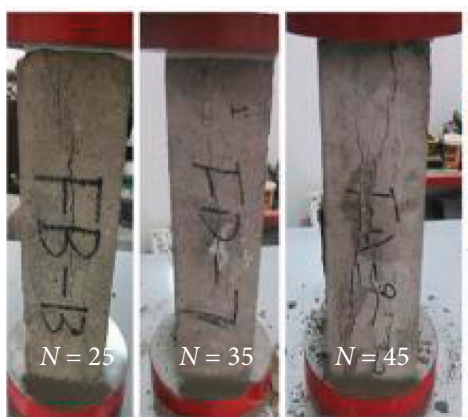

(c)
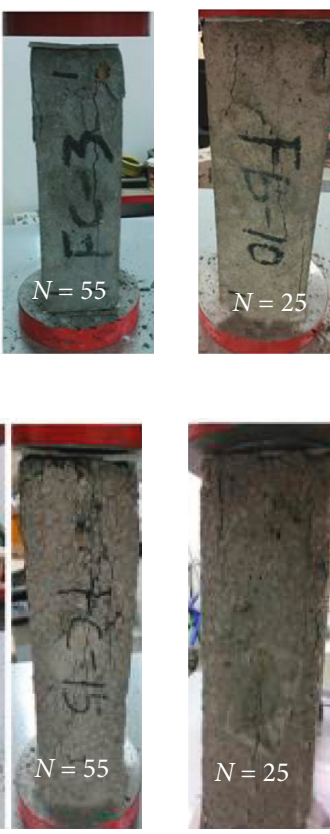

$=25$
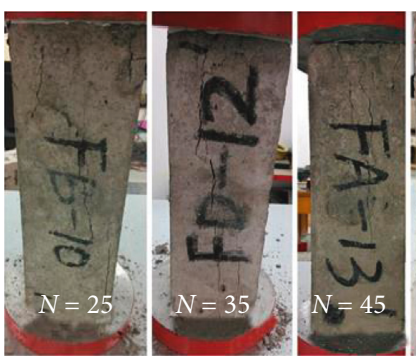

(b)

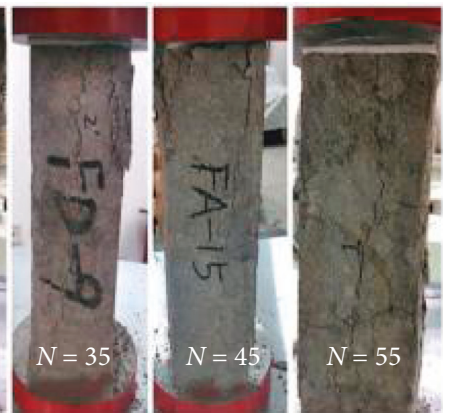

(d)

Figure 6: The failure modes of specimens after different freeze-thaw cycles and different temperatures cooled by spray water: (a) $20^{\circ} \mathrm{C}$, (b) $300^{\circ} \mathrm{C}$, (c) $400^{\circ} \mathrm{C}$, and (d) $500^{\circ} \mathrm{C}$.

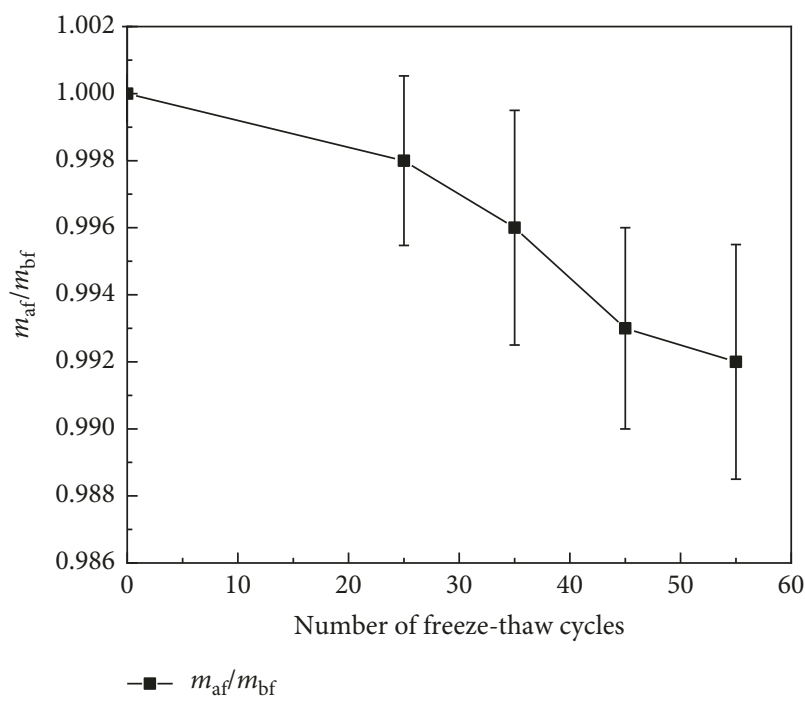

FIgURE 7: Variation in concrete weight ratio with increasing number of freeze-thaw cycles.

represents the compressive strength of the concrete after freeze-thaw cycles and then high-temperature treatment, and $f_{c}(0,20)$ represents the compressive strength of the unfrozen concrete at $20^{\circ} \mathrm{C}$. Figure 10 gives the effect of cooling methods on the relative compressive strength of specimens. From the figures, the following can be observed:

(a) With the number of freeze-thaw cycles and elevated temperatures, the relative compressive strength of concrete declines gradually. When the temperature is elevated from $20^{\circ} \mathrm{C}$ to $500^{\circ} \mathrm{C}$, the relative strengths

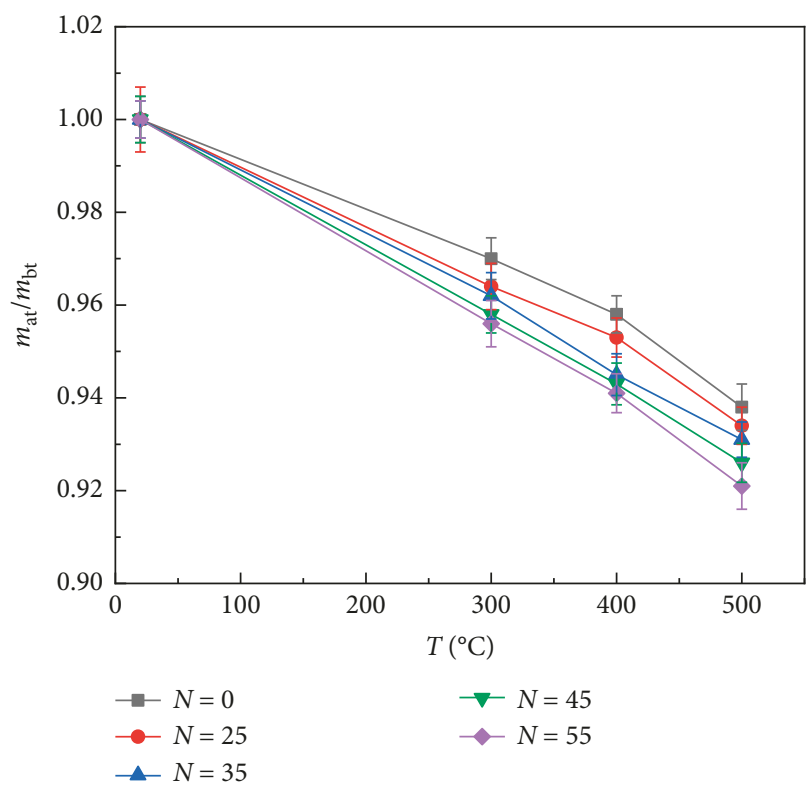

FIGURE 8: Variation in water-cooled concrete weight ratio with elevated temperatures.

of the freeze-thawed concrete specimens significantly degrade compared with those of the unfrozen ones at the same temperatures.

(b) The sequence of freeze-thaw cycle treatment and high-temperature treatment has effects on the degradation of compressive strength. The relative compressive strength of the concrete with 25 freezethaw cycles and then exposure to high temperature of 300,400 , and $500^{\circ} \mathrm{C}$ in this paper is lower than that 


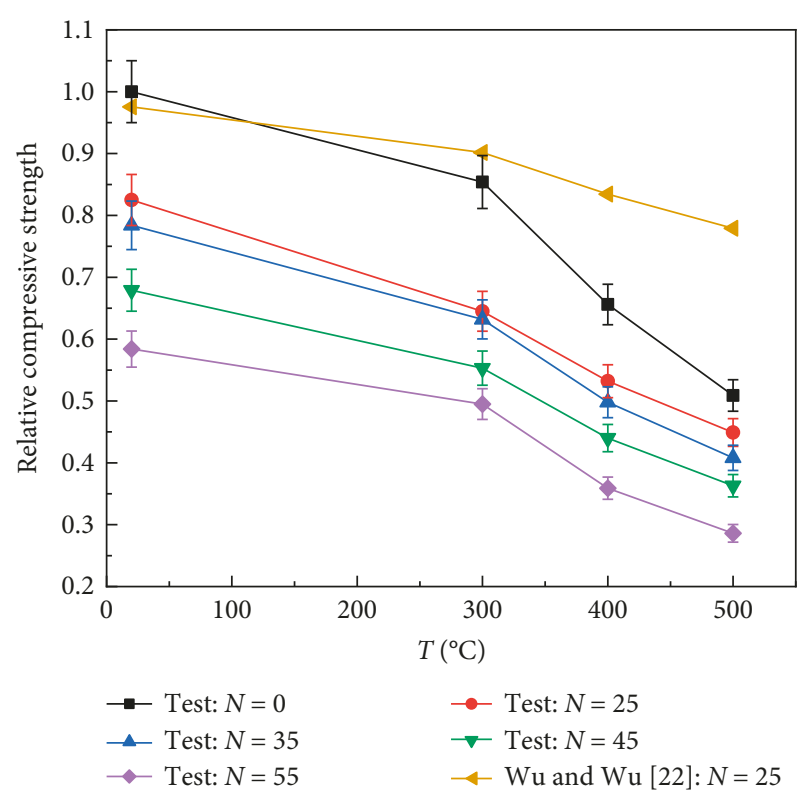

FIGURE 9: The relative compressive strength of the water-cooled concrete after freeze-thaw cycles and then exposure to high temperature.

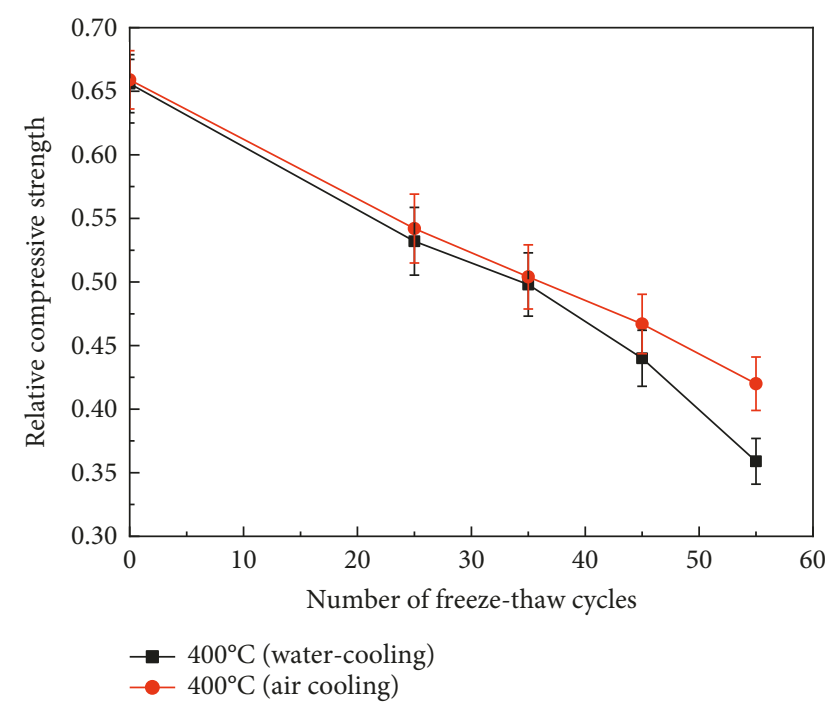

FIGURE 10: Effect of cooling methods on the relative compressive strength of concrete under different freeze-thaw cycles after exposure to high temperature.

of the concrete with exposure to high temperature of 300,400 , and $500^{\circ} \mathrm{C}$ and then with 25 freeze-thaw cycles studied by $\mathrm{Wu}$ and $\mathrm{Wu}$ [22]. This is mainly because for the concrete subjected to high-temperature treatment first, part of water reacts with $\mathrm{Ca}(\mathrm{OH})_{2}$ formed after exposure to high temperatures in subsequent freeze-thaw tests, resulting in the consequence that the deterioration of the strength partially restored.

(c) At $400^{\circ} \mathrm{C}$, the relative compressive strength of the concrete specimen under two different cooling methods decreases with the increasing freeze-thaw cycles. When $N<35$, the difference between different cooling modes is not obvious; but overall, the strength of the concrete after air-cooling is slightly greater than that of the water-cooled concrete. When $N \geq 35$, the relative compressive strength of the concrete specimen cooled by air is significantly greater than that of the concrete specimen cooled by spray water. As the number of freeze-thaw cycle increases, the trend becomes greater. This is mainly due to the influence of different cooling methods on the compressive properties of concrete. For watercooled concrete, the concrete specimen after exposure to high temperatures was suddenly cooled by water and the differences between the internal and external temperatures of the specimens increase rapidly, resulting in the rapid development of cracks.

Based on the test results, an empirical equation for water-cooled concrete specimens is as follows:

$$
\begin{aligned}
\frac{f_{\mathrm{c}}(N, T)}{f_{\mathrm{c}}(0,20)}= & 1.016-1.084 \times 10^{-4} T-7.370 \times 10^{-3} N \\
& -1.940 \times 10^{-6} \mathrm{NT}-1.777 \times 10^{-6} T^{2} \\
& +1.796 \times 10^{-8} T^{2} N .
\end{aligned}
$$

For the air-cooled concrete specimens, an influence coefficient $\beta(\mathrm{N})$ was introduced for the difference between air-cooling and water-cooling, and $\beta(N)=$ $1.0094+0.0001 \cdot N^{2}-0.0034 \cdot N$ was obtained by fitting the test results. Equation (1) can be modified for air-cooled concrete specimens as follows:

$$
\begin{aligned}
\frac{f_{\mathrm{c}}(N, T)}{f_{\mathrm{c}}(0,20)}= & \left(1.016-1.084 \times 10^{-4} T-7.370 \times 10^{-3} N\right. \\
& -1.940 \times 10^{-6} N T-1.777 \times 10^{-6} T^{2} \\
& \left.+1.796 \times 10^{-8} T^{2} N\right) \cdot \beta(N),
\end{aligned}
$$

where the letter $T$ represents the exposure temperature and the letter $N$ represents the number of freeze-thaw cycles.

Figure 11 shows a good agreement between equation (1) and tests, and the coefficient of correlation for equation (1) is 0.984 .

3.1.2. Degradation of Elastic Modulus of Concrete. The elastic modulus was defined as the secant modulus of the point with $\sigma=0.4 f_{c}$ in the stress-strain curve. The degradation of relative elastic modulus $E_{\mathrm{c}}(N, T) / E_{\mathrm{c}}(0,20)$ of the water-cooled concrete is shown in Figure 12. In which, $E_{\mathrm{c}}(N$, $T)$ represents the elastic modulus of the concrete specimen after $N$ cycles of freeze-thaw and then $T{ }^{\circ} \mathrm{C}$ treatment, and $E_{\mathrm{c}}(0,20)$ represents the elastic modulus of the unfrozen concrete at $20^{\circ} \mathrm{C}$. From Figure 12 , the following can be observed:

(a) The relative modulus of elasticity gradually reduces with the elevated number of freeze-thaw cycles and 


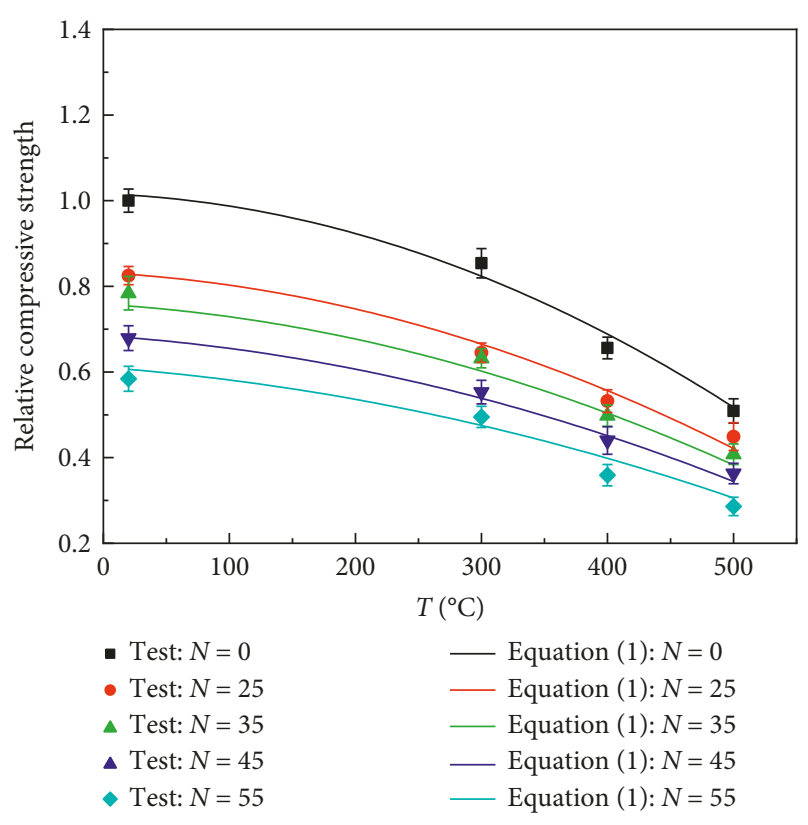

Figure 11: Comparison between calculated and test results.

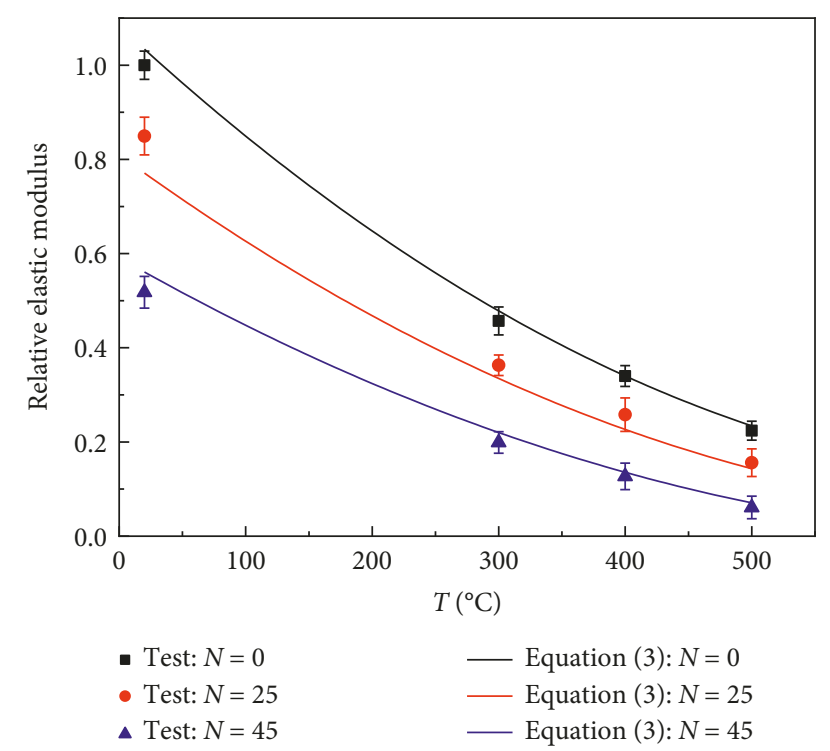

FIGURE 12: Relative elastic modulus of the water-cooled concrete after freeze-thaw cycles at different heating temperatures.

temperatures. The relative elastic modulus of freezethawed concrete specimens ( 25 and 45 cycles) is evidently lower than that of the unfrozen ones at the same temperature.

(b) As the temperature increases, the difference in relative elastic modulus of concrete specimens with different freeze-thaw cycles decreases. The greater the number of freeze-thaw cycles is, the smaller the relative elastic modulus there would be.

Using polynomial nonlinear fitting method, the calculation model of relative elastic modulus of the water-cooled concrete after freeze-thaw cycles and then exposure to high temperatures was established as follows:

$$
\begin{aligned}
\frac{E_{\mathrm{c}}(N, T)}{E_{\mathrm{c}}(0,20)}= & 0.9796+3.357 \times 10^{-4} \mathrm{~T}+3.349 \times 10^{-3} \mathrm{~N} \\
& +3.983 \times 10^{-5} \mathrm{~N} \cdot \mathrm{T}+8.700 \times 10^{-6} \mathrm{~T}^{2} \\
& -2.120 \times 10^{-8} \mathrm{~N} \cdot \mathrm{T}^{2},
\end{aligned}
$$

where the letter $T$ represents the exposure temperature and the letter $N$ represents the number of freeze-thaw cycles.

Figure 12 shows a good agreement between equation (3) and tests, and the coefficient of correlation for equation (3) is 0.987 .

3.1.3. Degradation of Peak Strain. The maximum strain before failure in the uniaxial compression test is the peak strain. Figure 13 shows the variation in relative peak strain $\varepsilon_{\mathrm{P}}$ $(N, T) / \varepsilon_{\mathrm{P}}(0,20)$ of the water-cooled concrete specimen. In which, $\varepsilon_{\mathrm{P}}(N, T)$ is the peak strain of the concrete specimen after $N$ cycles of freeze-thaw and then $T^{\circ} \mathrm{C}$ treatment, and $\varepsilon_{\mathrm{P}}$ $(0,20)$ is the unfrozen concrete peak strain at $20^{\circ} \mathrm{C}$. The effect of cooling methods on the peak strain is shown in Figure 14. From the figures, the following can be observed:

(a) The relative peak strain rises with the elevated temperatures. However, within each temperature range, the peak strain of the unfrozen specimen and the specimen subjected to 25 freeze-thaw cycles shows no significant difference, indicating the internal damage of the concrete specimen after 25 freeze-thaw cycles is very small. The peak strain of the concrete specimen after 45 cycles of freeze-thaw at $500^{\circ} \mathrm{C}$ is evidently larger than that of the unfrozen one at $20^{\circ} \mathrm{C}$. This is because the expansion of internal cracks and pores caused by freeze-thaw and hightemperature test leads to the increase of compaction zone and decline of axial stiffness of the concrete.

(b) The peak strain of the air-cooled concrete is significantly greater than that cooled by the spray water method under the same number of freeze-thaw cycles at $400^{\circ} \mathrm{C}$. It indicates that the ductility of the air-cooled concrete specimen is greater than that cooled by water. The difference between the peak strains of the concrete specimens under different cooling modes does not change significantly with the increase of the number of freeze-thaw cycles.

Based on the test results, the calculated model of the relative peak strain for the water-cooled concrete after freeze-thaw cycles and then exposure to high temperatures was established. Details are as follows:

$$
\begin{aligned}
\frac{\varepsilon_{\mathrm{P}}(N, T)}{\mathcal{E}_{\mathrm{P}}(0,20)}= & 0.9998-8.349 \times 10^{-4} T+6.263 \times 10^{-3} \mathrm{~N} \\
& +3.386 \times 10^{-5} \mathrm{~N} \cdot \mathrm{T}+1.354 \times 10^{-5} T^{2} \\
& -1.979 \times 10^{-9} \mathrm{~N} \cdot \mathrm{T}^{2},
\end{aligned}
$$




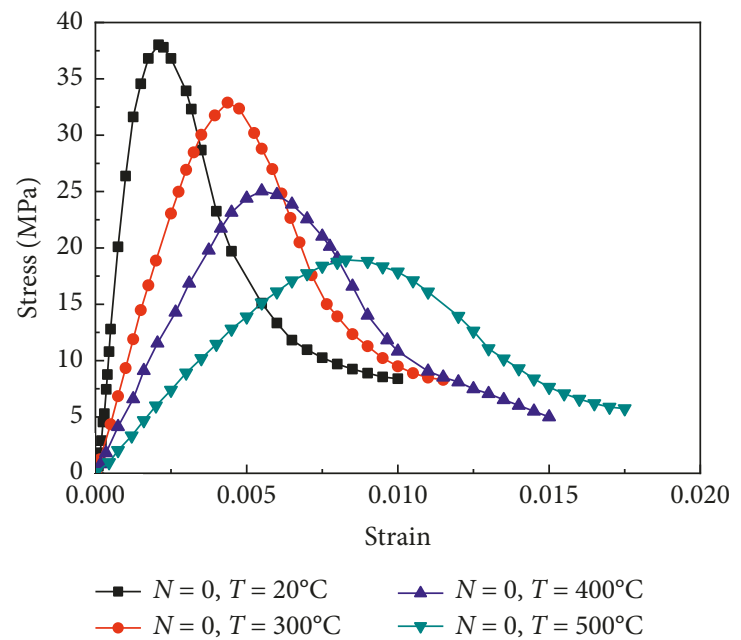

(a)

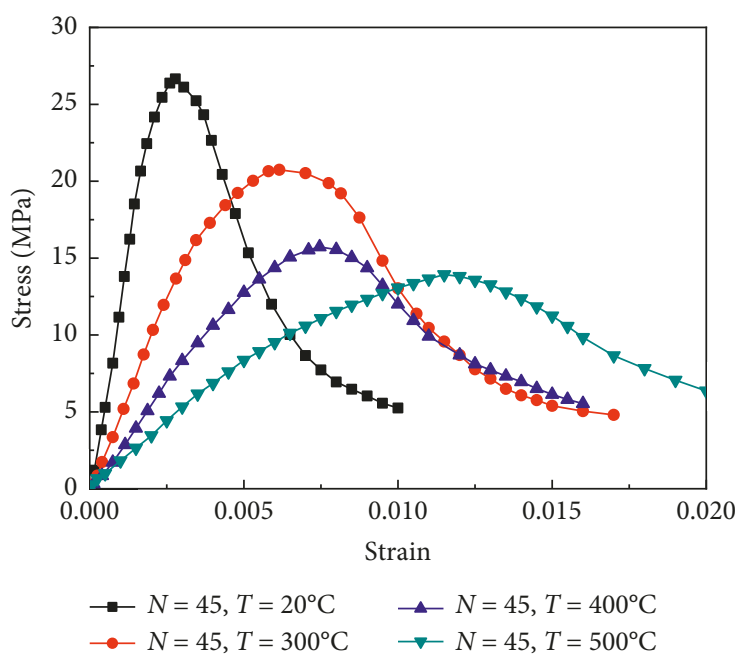

(c)

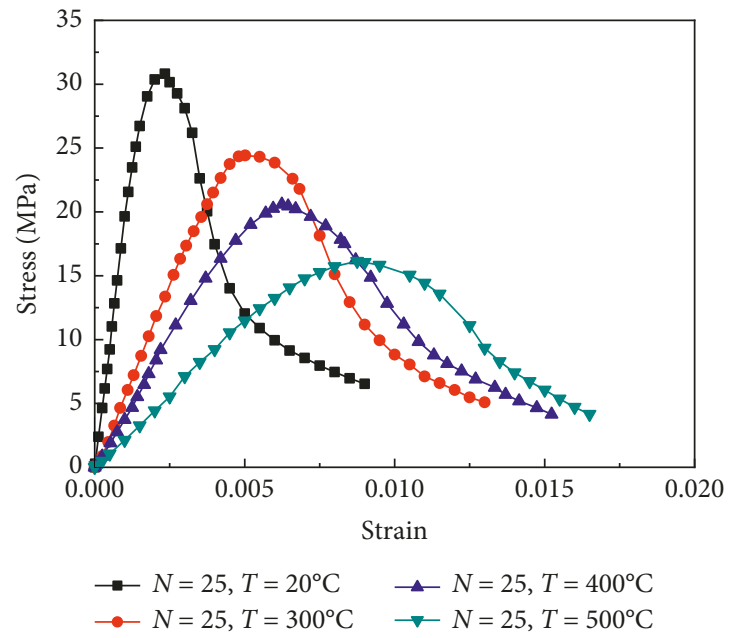

(b)

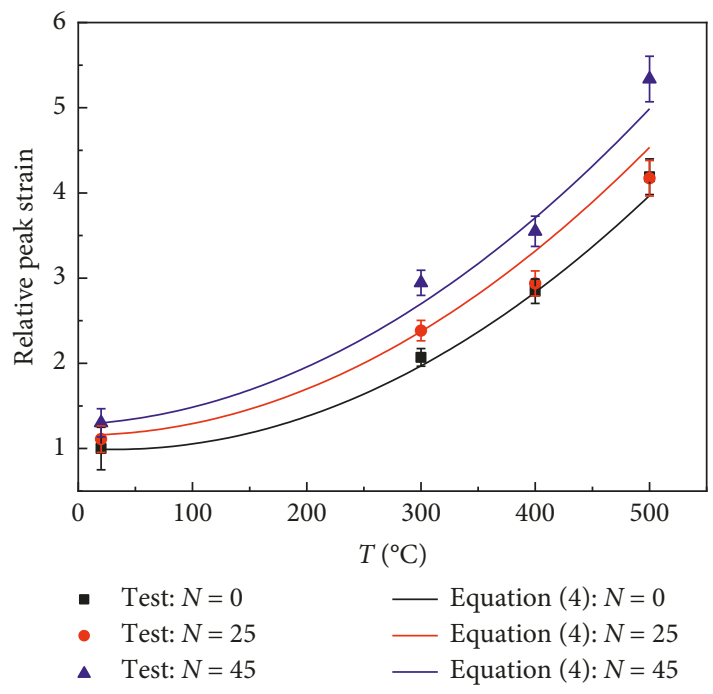

(d)

Figure 13: Strain of the water-cooled concrete after freeze-thaw cycles at different heating temperatures. (a) Stress-strain curves of the unfrozen concrete at different temperatures. (b) Stress-strain curves of the freeze-thawed concrete with 25 cycles at different temperatures. (c) Stress-strain curves of the freeze-thawed concrete with 45 cycles at different temperatures. (d) Relative peak strain after freeze-thaw cycles at different temperatures.

where the letter $T$ represents the exposure temperature and the letter $N$ represents the number of freeze-thaw cycles. A good agreement between equation (4) and tests is shown in Figure 13, and the coefficient of correlation for equation (4) is 0.972 .

\section{Constitutive Model of Concrete after Freeze- Thaw Cycles and Then High Temperatures}

Researches on constitutive model of freeze-thawed concrete after exposure to high temperatures are necessary to accurately evaluate the damage of freeze-thawed concrete structures in fire. According to the basic relationship of continuous damage mechanics [25], the damage constitutive model at room temperature was proposed as $\sigma=(1-D) E \varepsilon$, in which $D=$ $1-\exp \left(-\varepsilon^{m} / \alpha\right)$ [26]. In this paper, the investigation of the degradation of concrete was based on the uniaxial compression test but did not include complex stress state, so the damage variable $D$ is a scalar used for uniaxial compression.

For the concrete after exposure to high temperatures, the model was modified by adding the temperature coefficient, as shown $[19,27-30]$ in the following:

$$
\sigma=K_{\mathrm{T}}(T) \cdot \eta(T) \cdot E_{\mathrm{c}} \mathcal{E} \cdot \exp \left(-\frac{\varepsilon^{m}}{\alpha}\right)
$$

where $K_{\mathrm{T}}(T)$ is the temperature softening coefficient, $\eta(T)$ represents the strain correction coefficient, $\alpha$ represents the scale coefficient, and $m$ represents the shape influence coefficient.

In this paper, the following model was proposed based on equation (5) considering the effects of freeze-thaw cycles:

$$
\sigma=K_{\mathrm{F}}(N) \cdot K_{\mathrm{T}}(T) \cdot \eta(T) \cdot E_{\mathrm{c}} \varepsilon \cdot \exp \left(-\frac{\varepsilon^{m}}{\alpha(N, T)}\right),
$$




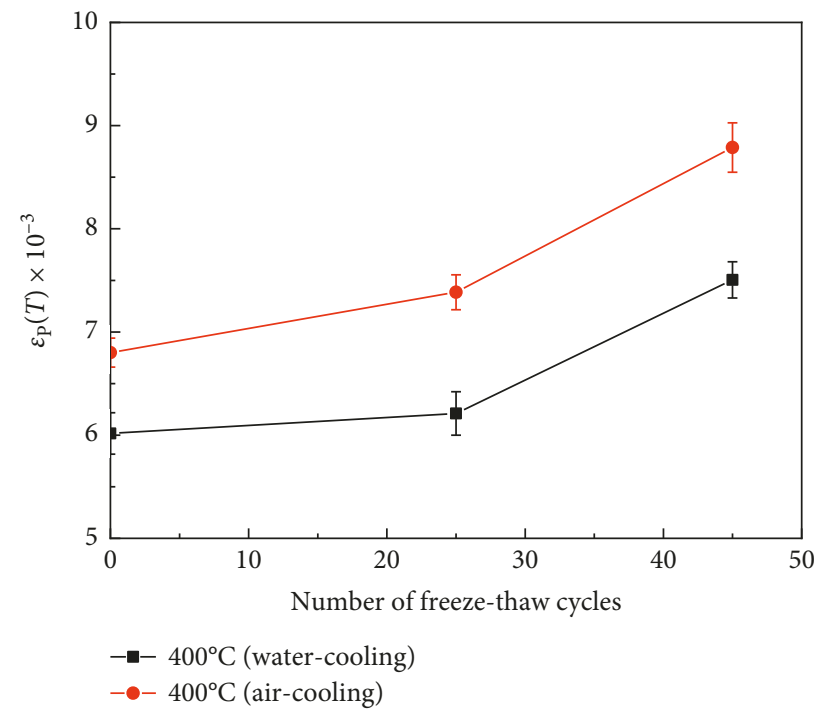

FIGURE 14: Effect of cooling methods on the peak strain of different freeze-thaw cycles concrete at $400^{\circ} \mathrm{c}$.

TABle 3: Parameters of the established compressive constitutive model.

\begin{tabular}{lcccc}
\hline Specimen & Freeze-thaw cycles & Exposure temperature $\left({ }^{\circ} \mathrm{C}\right)$ & $\eta(T)$ & $\alpha(N, T)$ \\
\hline F0-T20W & 0 & 20 & 1.000 & $3.798 \times 10^{-5}$ \\
F0-T300W & 0 & 300 & 0.855 & $1.272 \times 10^{-4}$ \\
F0-T400W & 0 & 400 & 0.685 & $1.967 \times 10^{-4}$ \\
F0-T500W & 0 & 500 & 0.548 & $3.909 \times 10^{-4}$ \\
F25-T20W & 25 & 20 & 1.000 & $3.702 \times 10^{-5}$ \\
F25-T300W & 25 & 300 & 0.855 & 1.75 \\
F25-T400W & 25 & 400 & 0.685 & 1.75 \\
F25-T500W & 25 & 500 & 0.548 & $2.074 \times 10^{-4}$ \\
F45-T20W & 45 & 20 & 1.000 & $3.186 \times 10^{-4}$ \\
F45-T300W & 45 & 300 & 0.855 & $6.009 \times 10^{-5}$ \\
F45-T400W & 45 & 400 & 0.685 & $2.125 \times 10^{-4}$ \\
F45-T500W & 45 & 500 & 0.548 & $3.206 \times 10^{-4}$ \\
\end{tabular}

where $K_{\mathrm{F}}(N)$ is the freeze-thaw cycle softening parameter. $K_{\mathrm{F}}(N)$ and $K_{\mathrm{T}}(T)$ are, respectively, expressed as

$$
\begin{gathered}
K_{\mathrm{F}}(N)=\frac{E_{\mathrm{c}}(N)}{E_{\mathrm{c}}}=1.0-2.45 \times 10^{-3} N-1.67 \times 10^{-4} N^{2}, \\
K_{\mathrm{T}}(T)=\frac{E_{\mathrm{c}}(T)}{E_{\mathrm{c}}}=1.047-2.410^{-3} \times T+1.533 \times 10^{-6} T^{2} .
\end{gathered}
$$

Based on the test results and using the least-squares method, the parameters in constitutive model equation (6) are determined and are shown in Table 3 and equations (8) and (9):

$$
\begin{aligned}
\eta(T)= & 1+1.56 \times 10^{-5} T-1.937 \times 10^{-6} T^{2} \\
\alpha(N, T)= & 4.013 \times 10^{-5}-2.900 \times 10^{-7} \cdot T+7.281 \times 10^{-7} \\
& \cdot N-1.128 \times 10^{-8} \cdot T \cdot N+1.674 \times 10^{-9} \cdot T^{2} \\
& +4.452 \times 10^{-11} \cdot T^{2} \cdot N .
\end{aligned}
$$

Comparison between the calculated data (in this paper, $\left.E_{\mathrm{c}}=30134 \mathrm{MPa}\right)$ obtained from the established uniaxial compression constitutive model (i.e., Equation (6)) and test

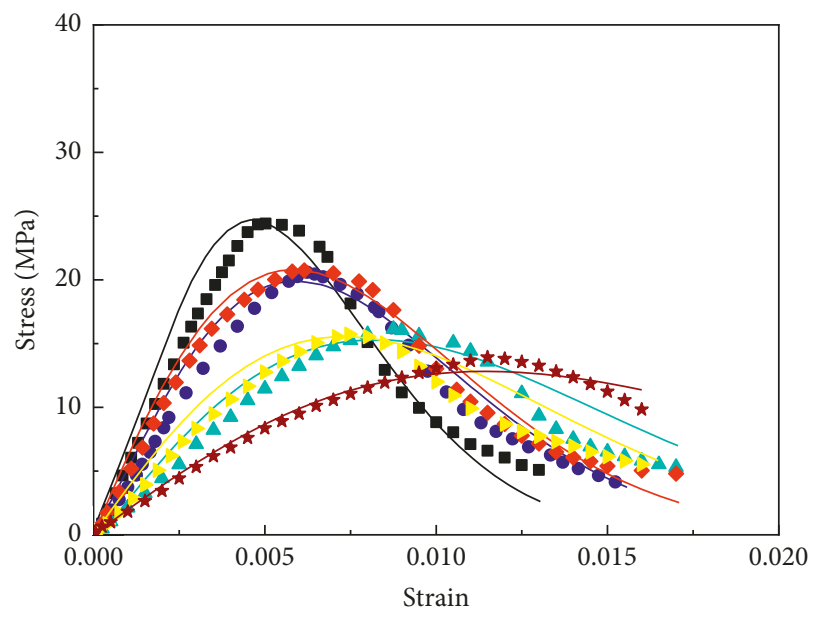

- Test: $N=25, T=300$ Equation (6): $N=25, T=300$

- Test: $N=25, T=400$ Equation (6): $N=25, T=400$

$\Delta$ Test: $N=25, T=500$ — Equation (6): $N=25, T=500$

- Test: $N=45, T=300$ Equation (6): $N=45, T=300$

Dest: $N=45, T=400 \longrightarrow$ Equation (6): $N=45, T=400$

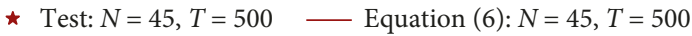

FIgURE 15: Comparison between the calculated value and experimental results. 
results are shown in Figure 15, and a good agreement can be observed.

\section{Conclusions}

Based on the test results, the conclusions can be summarized as follows:

(a) The surface color of the concrete does not change significantly throughout the test. In the freezethawed concrete after exposure temperature of $400^{\circ} \mathrm{C}$, the cracks can be clearly seen on the concrete surfaces and were more significant for concrete with more freeze-thaw cycles.

(b) As the number of freeze-thaw cycles and temperatures increase, the weight loss of the concrete increases. However, within a range of $0-55$ freeze-thaw cycles and $20-500^{\circ} \mathrm{C}$, the weight loss is relatively small, only $8 \%$.

(c) The relative compressive strength and modulus of elasticity of concrete decreased with the freeze-thaw cycles or temperature increase. After freeze-thaw cycles, the relative strength and elastic modulus of the concrete specimens significantly degrade compared with those of the unfrozen ones at same temperatures. For the concrete with the same freezethaw cycles and temperatures, the damaged degree is relative to the sequence of the freeze-thaw cycles and high-temperature treatment.

(d) As the number of freeze-thaw cycles and temperatures increase, the peak strain of the concrete increases. And there is no significant difference between the relative peak strain of the freeze-thawed concrete with 25 cycles and the unfrozen concrete.

(e) Cooling methods have different effects on the degradation of concrete under different number of freeze-thaw cycles. When $N \leq 35$, there is no significant difference in the effect of different cooling methods on compressive strength, but when $N>35$, water-cooling is more disadvantageous on the compressive strength of concrete.

(f) A constitutive model for uniaxial compression concrete after freeze-thaw cycles and then exposure to high temperatures was established and a good agreement can be seen with the test results.

\section{Data Availability}

All data analyzed during this study are included in this article.

\section{Conflicts of Interest}

The authors declare that they have no conflicts of interest.

\section{Acknowledgments}

The authors of this paper gratefully acknowledge the funding support received from the National Natural Science
Foundation of China (Grant no. 51878550) and the project of the Education Department of Shaanxi Provincial Government of China (Grant nos. 18JS066 and 2014SZS04-P05).

\section{References}

[1] M. Henry, I. S. Darma, and T. Sugiyama, "Analysis of the effect of heating and re-curing on the microstructure of highstrength concrete using X-ray CT," Construction and Building Materials, vol. 67, pp. 37-46, 2014.

[2] X. Luo, W. Sun, and Y. N. Chan, "Residual compressive strength and microstructure of high performance concrete after exposure to high temperature," Materials and Structures, vol. 33, no. 5, pp. 294-298, 2012.

[3] A. H. Akca and N. Özyurt, "Effects of re-curing on microstructure of concrete after high temperature exposure," Construction and Building Materials, vol. 168, pp. 431-441, 2018.

[4] Y. F. Chang, Y. H. Chen, M. S. Sheu, and G. C. Yao, "Residual stress-strain relationship for concrete after exposure to high temperatures," Cement and Concrete Research, vol. 36, no. 10, pp. 1999-2005, 2006.

[5] B. Chen, C. Li, and L. Chen, "Experimental study of mechanical properties of normal-strength concrete exposed to high temperatures at an early age," Fire Safety Journal, vol. 44, no. 7, pp. 997-1002, 2009.

[6] Y. Zhai, Z. Deng, N. Li, and R. Xu, "Study on compressive mechanical capabilities of concrete after high temperature exposure and thermo-damage constitutive model," Construction and Building Materials, vol. 68, no. 3, pp. 777-782, 2014.

[7] W. Ren, J. Xu, and H. Su, "Dynamic compressive behaviour of concrete after exposure to elevated temperatures," Materials and Structures, vol. 49, no. 8, pp. 3321-3334, 2016.

[8] S. Hassen and H. Colina, "Effect of a heating-cooling cycle on elastic strain and Young's modulus of high performance and ordinary concrete," Materials and Structures, vol. 45, no. 12, pp. 1861-1875, 2012.

[9] S. Hassen and H. Colina, "Effect of heating-cooling cycles on transient creep strain of high performance, high strength and ordinary concrete under service and accidental conditions," Materials \& Structures, vol. 48, no. 5, pp. 1561-1579, 2015.

[10] H. Q. Yan, Y. Peng, and Q. Y. Wang, "Experimental research on thermal mechanical behavior of recycled aggregate concrete from earthquake-stricken area," Advanced Materials Research, vol. 217-218, pp. 1081-1085, 2011.

[11] Y. Zhai, X. C. Ai, Z. C. Deng, and W. He, "Influence of cooling mode and high temperature on concrete compressive strength," Journal of Hunan University (Natural Sciences), vol. 41, no. 11, pp. 74-80, 2014.

[12] H. Yu, H. Ma, and K. Yan, "An equation for determining freeze-thaw fatigue damage in concrete and a model for predicting the service life," Construction and Building Materials, vol. 137, pp. 104-116, 2017.

[13] J. Yuan, Y. Liu, H. Li, and B. Zhang, "Experimental investigation of the variation of concrete pores under the action of freeze-thaw cycles by using X-Ray CT," Advances in Materials Science and Engineering, vol. 2014, Article ID 571357, 11 pages, 2014.

[14] T. Suzuki, T. Shiotani, and M. Ohtsu, "Evaluation of cracking damage in freeze-thawed concrete using acoustic emission and X-ray CT image," Construction and Building Materials, vol. 136, pp. 619-626, 2016. 
[15] H.-S. Shang, Y.-P. Song, and L.-K. Qin, "Experimental study on strength and deformation of plain concrete under triaxial compression after freeze-thaw cycles," Building and Environment, vol. 43, no. 7, pp. 1197-1204, 2008.

[16] W. L. Song, X. F. Li, and K. F. Ma, "The effect of freeze-thaw cycles on mechanical properties of concrete," Advanced Materials Research, vol. 163-167, pp. 3429-3432, 2010.

[17] H.-s. Shang and Y.-p. Song, "Behavior of air-entrained concrete under the compression with constant confined stress after freeze-thaw cycles," Cement and Concrete Composites, vol. 30, no. 9, pp. 854-860, 2008.

[18] H.-s. Shang, W.-q. Cao, and B. Wang, "Effect of fast freezethaw cycles on mechanical properties of ordinary-airentrained concrete," Scientific World Journal, vol. 2014, Article ID 923032, 7 pages, 2014.

[19] Q. Xie, L. Zhang, S. Yin, B. Zhang, and Y. Wu, "Effects of high temperatures on the physical and mechanical properties of carbonated ordinary concrete," Advances in Materials Science and Engineering, vol. 2019, Article ID 5753232, 10 pages, 2019.

[20] M. Mao, D. Zhang, Q. Yang, and W. Zhang, "Study of durability of concrete with fly ash as fine aggregate under alternative interactions of freeze-thaw and carbonation," Advances in Civil Engineering, vol. 2019, Article ID 4693893, 15 pages, 2019.

[21] Y. Cheng, Y. Zhang, Y. Jiao, and J. Yang, "Quantitative analysis of concrete property under effects of crack, freezethaw and carbonation," Construction and Building Materials, vol. 129, pp. 106-115, 2016.

[22] Y. Wu and B. Wu, "Residual compressive strength and freezethaw resistance of ordinary concrete after high temperature," Construction and Building Materials, vol. 54, pp. 596-604, 2014.

[23] GB/T50081-2002, Standard for Test Method of Mechanical Properties on Ordinary Concrete, National Standard of the People's Republic of China, Beijing, China, 2002.

[24] GB/T50082-2009, Standard for Test Methods of Long-Term Performance and Durability of Ordinary Concrete, National Standard of the People's Republic of China, Beijing, China, 2009.

[25] G. Z. Voyiadjis and Z. N. Taqieddin, "Elastic plastic and damage model for concrete materials: part I-theoretical formulation," International Journal of Structural Changes in Solids-Mechanics and Application, vol. 01, pp. 31-59, 2009.

[26] Z. Wu and C. J. Zhang, "Investigation of rock damage model and its mechanical behavior," Chinese Journal of Rock Mechanics and Engineering, vol. 01, pp. 55-61, 1996.

[27] W. Li and Z. H. Guo, "Experimental investigation of strength and deformation of concrete at elevated temperature," Journal of Building Structures, vol. 14, no. 13, pp. 8-16, 1993.

[28] B. Jia, Z. L. Li, L. Cheng, and H. C. Yao, "Experimental study on dynamic mechanical behaviour of concrete with high temperature," Advanced Materials Research, vol. 194-196, pp. 1109-1113, 2011.

[29] R. Tenchev and P. Purnell, "An application of a damage constitutive model to concrete at high temperature and prediction of spalling," International Journal of Solids and Structures, vol. 42, no. 26, pp. 6550-6565, 2005.

[30] D. Gawin, F. Pesavento, and B. A. Schrefler, "Modelling of hygro-thermal behaviour of concrete at high temperature with thermo-chemical and mechanical material degradation," Computer Methods in Applied Mechanics and Engineering, vol. 192, no. 13-14, pp. 1731-1771, 2003. 


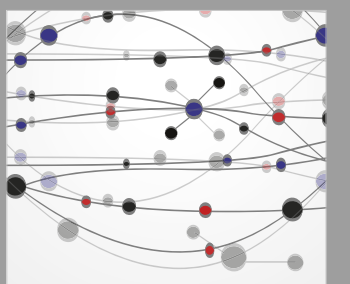

The Scientific World Journal
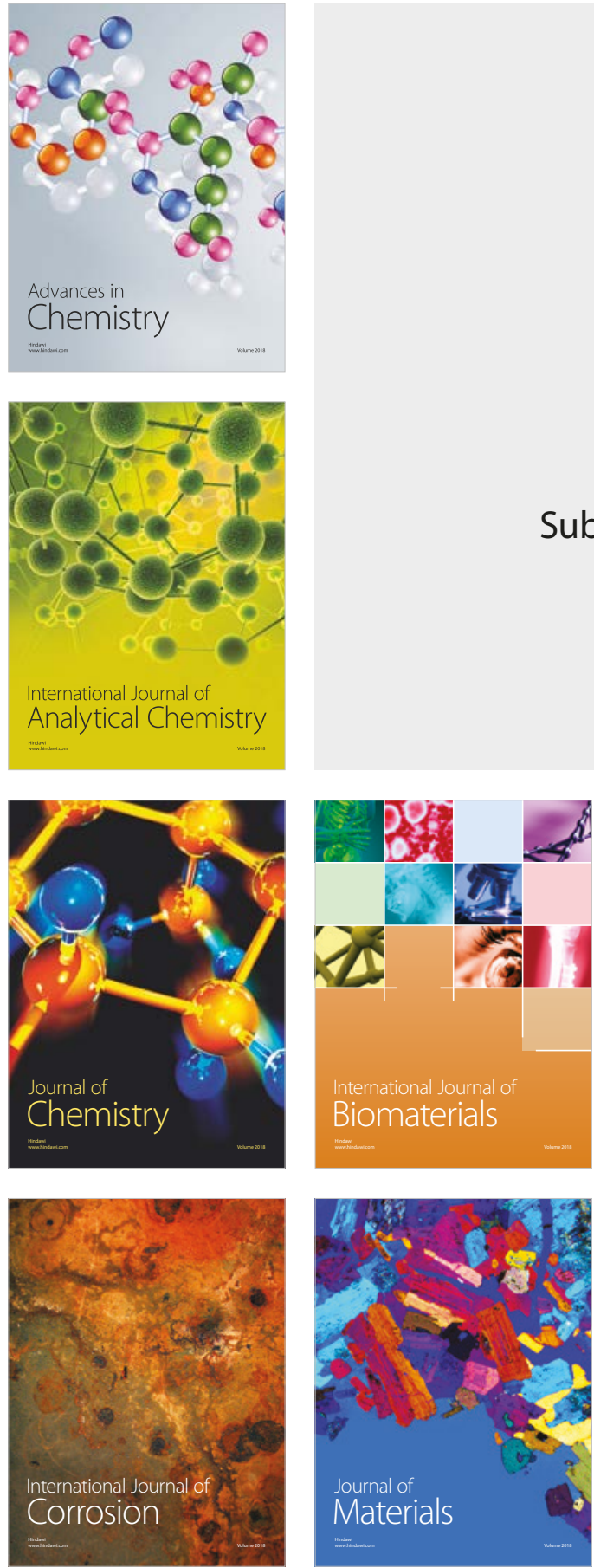

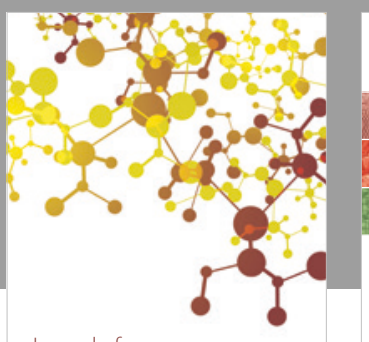

Journal of

Applied Chemistry
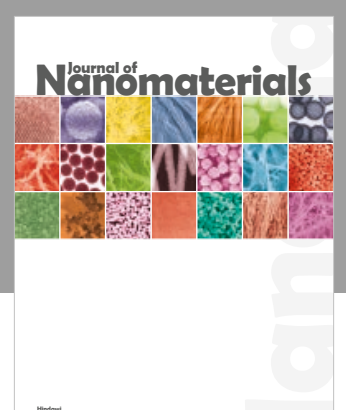

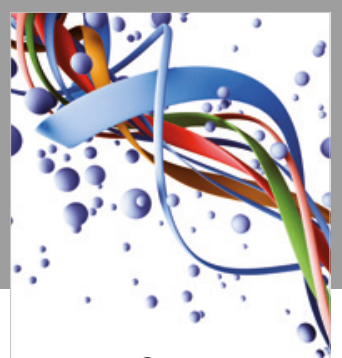

Scientifica

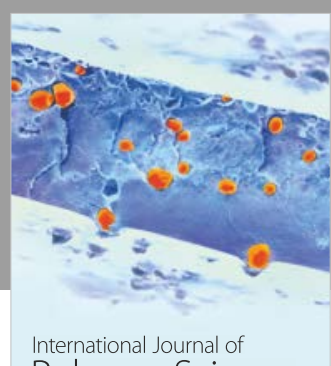

Polymer Science

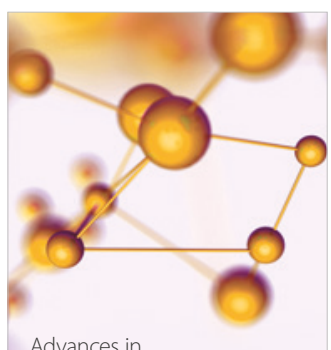

Physical Chemistry
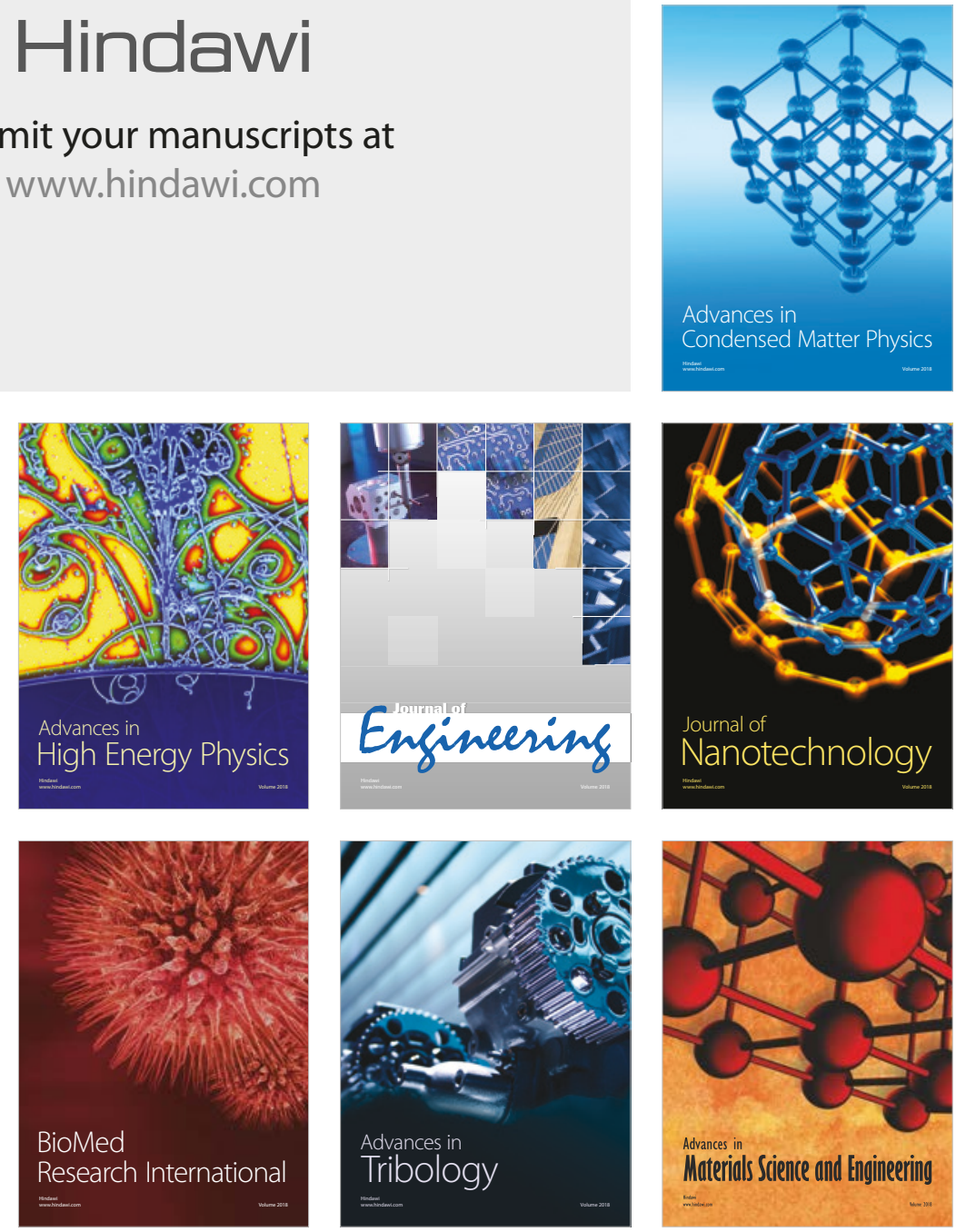